Article

\title{
Experimental Study on Hydraulic Conductivity and Resistance in Silty Sediments
}

\author{
Wenlong Zhu ${ }^{1}$, Minxi Zhang ${ }^{1}$, Hui Sun ${ }^{2}$ and Guoliang $\mathrm{Yu}^{1, *}$ \\ 1 State Key Laboratory of Ocean Engineering, Collaborative Innovation Center for Advanced Ship and \\ Deep-Sea Exploration, School of Naval Architecture, Ocean and Civil Engineering, \\ Shanghai Jiao Tong University, Shanghai 200240, China; zhuwenlong-sjtu@sjtu.edu.cn (W.Z.); \\ zmx8888@163.com (M.Z.) \\ 2 China Communications Construction Company, National Engineering Research Center Dredging Technology \\ and Equipment CO., LTD., Shanghai 200082, China; sunhui@cccc-drc.com \\ * Correspondence: yugl@sjtu.edu.cn; Tel.: +86-134-8215-0851
}

check for updates

Citation: Zhu, W.; Zhang, M.; Sun, H.; Yu, G. Experimental Study on Hydraulic Conductivity and Resistance in Silty Sediments. Water 2021, 13, 75. https://doi.org/10.3390/ w13010075

Received: 26 October 2020 Accepted: 26 December 2020 Published: 31 December 2020

Publisher's Note: MDPI stays neutral with regard to jurisdictional clai$\mathrm{ms}$ in published maps and institutional affiliations.

Copyright: (C) 2020 by the authors. Licensee MDPI, Basel, Switzerland. This article is an open access article distributed under the terms and conditions of the Creative Commons Attribution (CC BY) license (https:// creativecommons.org/licenses/by/ $4.0 /)$.

\begin{abstract}
Hydraulic conductivity $k$ as a function of void ratio $e$ and particle diameter for silty sediment was experimentally investigated, and an empirical formula for the estimation of hydraulic conductivity was proposed. Seepage resistance for flow in silty sediment was deliberated. Based on the findings of the study, it was concluded that hydraulic conductivity $k$ could be expressed as an exponential function of void ratio $e$ and median particle diameter $d_{50}\left\{3.1 \mu \mathrm{m}<d_{50}<87 \mu \mathrm{m}\right.$ and $0.26<e<4$ \}. It was further found that the formula of seepage resistance factor $(\lambda)$, a form of friction factor, varies linearly with Reynolds number $\left(R_{e}\right)$ for silty sediments. A family of such $\lambda$ - $R_{e}$ curves for various particle diameter $d_{50}$ is presented.
\end{abstract}

Keywords: seepage; void ratio; grain size; Reynolds number

\section{Introduction}

Utilization of dredged fine sediments has attracted wide attention in recent years. In China, the total quantity of dredged fine sediments was 395.5 million $\mathrm{m}^{3}$ in 2017, and that included 169 million $\mathrm{m}^{3}$ from various construction activities related to coastal reservoirs, ports and waterways, 10.3 million $\mathrm{m}^{3}$ from the maintenance of reservoirs, ports and waterways, 142.2 million $\mathrm{m}^{3}$ from land reclamation, and 74 million $\mathrm{m}^{3}$ from various environmental projects. Naturally, these dredged soils are mainly composed of clay, silt, mud, and a certain amount of silty sand/sandy particles. Grain size distribution shows a wide grading range. Soil characteristics are different from those of sandy granular materials, as dredged materials exhibit certain cohesive characteristics, low permeability, and weak bearing capacity. In the past, these dredged materials were difficult to use and were dumped in certain designated sites instead. However, with sandy material in short supply today, and river/beach sand mining viewed as being not environmentally friendly, engineers and developers have sought to utilize dredged materials as landfill materials instead of dumping them as waste [1]. Other uses include creation of certain fish and wildlife habitats $[2,3]$. Such use of dredged fine sediments (with appropriate engineering considerations and treatments) would be the modus operandi of our time and the time to come. For example, the Leqing port, a major satellite facility of the Wenzhou Port in the Zhejiang province of China, was recently hydraulically reclaimed using dredged clay slurry as landfill material. This clay slurry was dredged from the port basin and waterways at the coastal regions and hydraulically piped to the land reclamation area. The hydraulically filled area was over 7000 acres and up to $6.5 \mathrm{~m}$ in depth. Median particle diameter and initial water content of the dredged soil were $7.26 \mu \mathrm{m}$ and $175 \%$ or higher by volume, respectively. Due to the low permeability and strong ability to bind water, the bearing capacity of the reclaimed land was still very low many weeks later [4]. 
Leachate from land filled with dredged material may have serious concerns in terms of environmental safety, stability of the reclaimed land, and the infrastructure built on said land. The leachate with hazardous pollutants might affect the quality of the groundwater [5-7]. Release of water through seepage or consolidation of slurry materials would lead to settlement and may induce slope failure and cofferdam breaches [8-10]. It has been reported that silty/muddy materials typically exhibit certain distinct physical characteristics very much different from those of noncohesive granular sediments. Grain size of silty/muddy sediment measures in microns, and grain size distribution typically covers several orders of magnitude and the specific surface area of the particle is large [11]. This fine soil exhibits strong cohesive and viscous characteristics. As a result, seepage flow through the tortuous passages of silty sediments is complex due to interactions between the fluid and fine particles [12].

There are many reported studies on seepage flow through sedimentary beds, but the details on seepage flow in silty sediments are still controversial [13]. The key parameter used to describe seepage flow is hydraulic conductivity. Equations (1)-(7) are some of the reported formulae used to calculate hydraulic conductivity $k$ of sedimentary beds [14-22]:

$$
\begin{gathered}
k=A\left(d_{10}^{2}\right) \\
\log k=\log k_{0}-\frac{e_{0}-e}{C_{k}} \\
\log k=A(\log e)+B \\
k=C_{F} \frac{1}{S^{2}} \frac{\mathrm{e}^{3}}{(1+e)} \frac{r_{w}}{\mu \rho_{m}^{2}} \\
k=\frac{\varepsilon^{3}}{(1-\varepsilon)^{2}}\left(\frac{r_{w}}{\mu}\right)\left(\frac{d_{m}^{2}}{180}\right) \\
k=\frac{\varepsilon^{3}}{5(1-\varepsilon)^{2}}\left(\frac{d_{50}}{6}\right)^{2} \\
\ln k=7.617+3.486(\ln e)+1.235\left(\ln d_{50}\right)
\end{gathered}
$$

where $e, e_{0}, \varepsilon$, and $k_{0}$ are void ratio and initial void ratio, porosity, and initial hydraulic conductivity of sedimentary beds; $C_{F}, S, \rho_{m}$, and $d_{m}$ are shape coefficient, specific surface area, density, and size of grains that are $\mathrm{x} \%$ (by weight) finer than the specified diameter of the sediment particle; $r_{w}$ is unit weight; $\mu$ is coefficient of dynamic viscosity of seepage flow; $A, B$, and $C_{k}$ are coefficients. Among the many factors that affect hydraulic conductivity of silty soil, particle diameter and void ratio are the two major factors. However, there is no consensus on how these factors influence hydraulic conductivity of fine silty sediments. Taylor [17] suggested that an empirical linear relationship exists between the logarithm of $k$ and void ratio $e$, while Mesri and Olson [18] proposed that a linear relationship exists between $\log k$ and $\log e$. Others believed that $k$ is proportional to $e^{n} /(1+e)[19,20]$. Some researchers indicated that hydraulic conductivity is affected by effective particle diameter $d_{10}$ [23,24]. Chen et al. [25] found that hydraulic conductivity is strongly related to median diameter $d_{50}$. Some researchers even doubt whether these equations are sufficiently accurate for a silty sediment $[26,27]$.

In addition, seepage resistance in silty sediment still needs to be investigated. Seepage resistance through a porous medium is generally characterized by the friction factor $\lambda$ and Reynolds number $R_{e}$, where the parameters $\lambda$ and $R_{e}$ represent the resistance to flow past the sediment particles and the flow regime, respectively. There are many studies on seepage resistance, but most are focused on packed beds. Ergun equation [28,29] is one 
of the representative equations that describes the seepage resistance-Reynolds number relation for fluid flow through packed beds, which can be written as:

$$
\lambda=1.75+150 \frac{1-\varepsilon}{R_{e}}
$$

where $\varepsilon$ is soil porosity. Macdonald et al. [30] and Moutsopoulos et al. [31] suggested that the gradation of silty sediment might also have important influence on flow resistance. In the case of dredged cohesive sediments, the soils usually exhibit certain rheological properties and behave as a viscous fluid [1]. The rheological behaviors of dense cohesive sediments are typically non-Newtonian and non-time-invariant. The rheological properties of cohesive sediments subject to shear loads are sensitive to both shear rate and time. The internal structures of bulk cohesive sediments with the same water content and sediment grain size may vary due to their different settlement histories [32,33]. Therefore, one would expect that resistance to seepage in silty sediments would be distinctly different from that in porous media composed of coarse grain materials. Thus, the reported seepage resistance models may not be applicable to silty sediments, and a new seepage resistance model needs to be developed.

The aim of this study is to investigate hydraulic conductivity and seepage resistance in a silty cohesive soil. For this purpose, extensive seepage tests were planned, designed, and the experiments carried out using a cylindrical permeameter for seven types of silty sediments. Grain size distribution, hydraulic conductivity, and Reynolds number were measured. The variation of hydraulic conductivity with void ratio for various silty sediments was examined and analyzed, and a formula for calculating seepage resistance in silty sediment beds was developed. The relationship between seepage resistance and particle Reynolds number was deliberated in detail.

\section{Material and Methods}

Thirty-five sets of seepage experiments were conducted at the coastal laboratory in Shanghai Jiao Tong University. The experimental setup and procedures are described herein.

\subsection{Experimental Setup}

A standard cylindrical permeameter (TST-55 type, Nanjing Nantu Instrument Equipment Co. LTD., Nanjing, China) was used for the seepage experiments, see Figure 1. The permeameter was $118 \mathrm{~mm}$ in outer diameter, and $155 \mathrm{~mm}$ high. The test sample inside the permeameter was $61.8 \mathrm{~mm}$ in diameter and $40 \mathrm{~mm}$ high (the shortest seepage path in the test sample $L=40 \mathrm{~mm}$ ). Both the upper and lower porous stones were $61.8 \mathrm{~mm}$ in diameter and $10 \mathrm{~mm}$ high. The permeability coefficient of the porous stone was greater than $10^{-3} \mathrm{~cm} / \mathrm{s}$, which was much higher than that of the silty sediment samples.

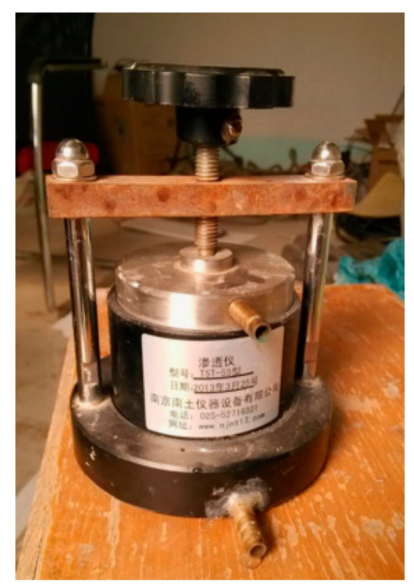

Figure 1. TST-55 permeameter. The TST-55 permeameter consisted of a cutting ring, two porous stones, a lantern ring, a top cover, a bottom cover, two rubber rings, and secured with bolts and nuts. 
A constant water head flow condition was set up in these experiments, see Figure 2. Two piezometers were installed at the inlet and outlet of the permeameter to measure the respective water head, and the water head difference $\Delta h$ between them. The outflow water was collected in a glass cylinder and weighed using an electronic balance $( \pm 0.01 \mathrm{~g})$ to determine mass flowrate. Bulk seepage velocity was calculated accordingly, and hydraulic conductivity was calculated based on Darcy's law.

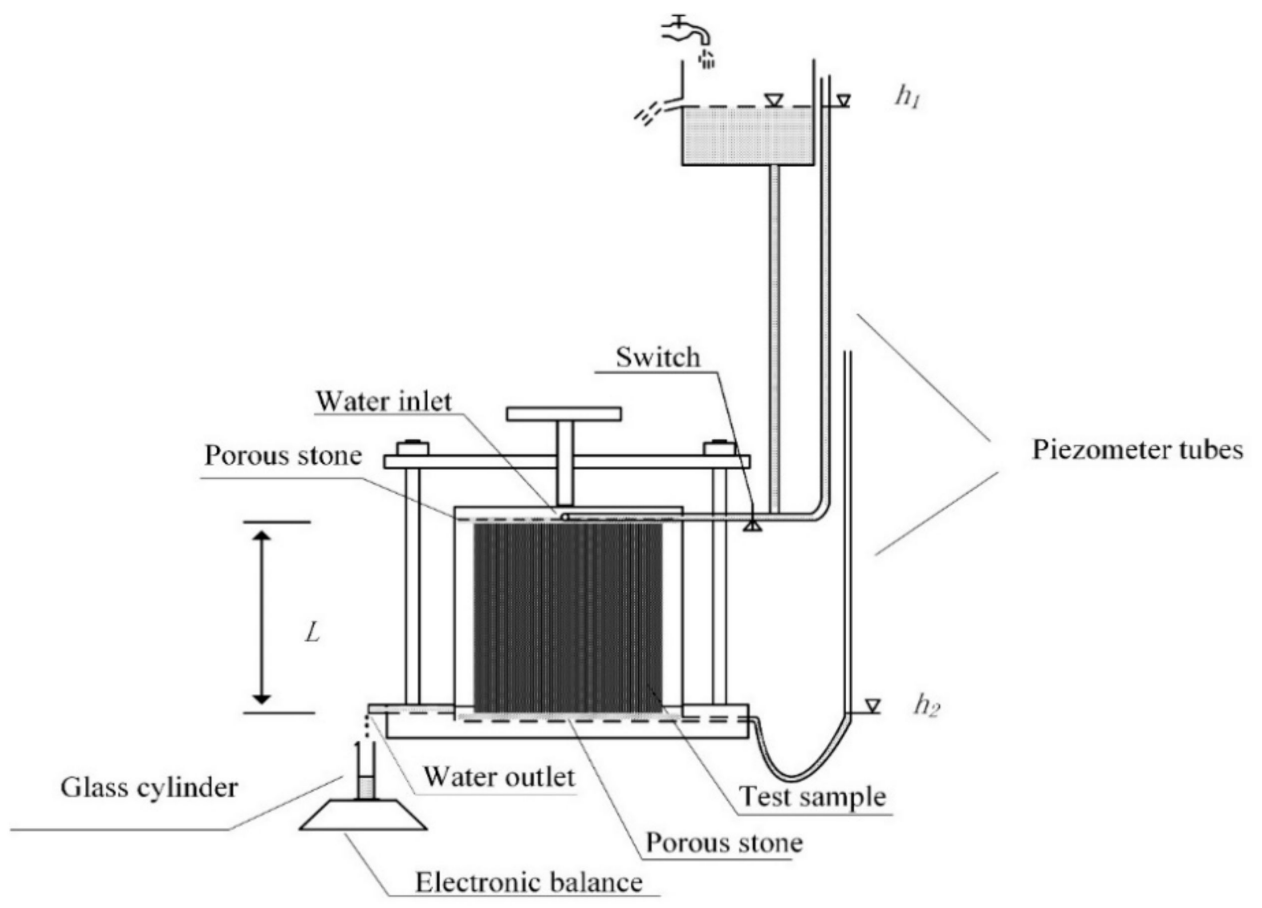

Figure 2. Schematic diagram of the experimental setup. The outflow water was collected in a glass cylinder and weighed using an electronic balance under the glass cylinder.

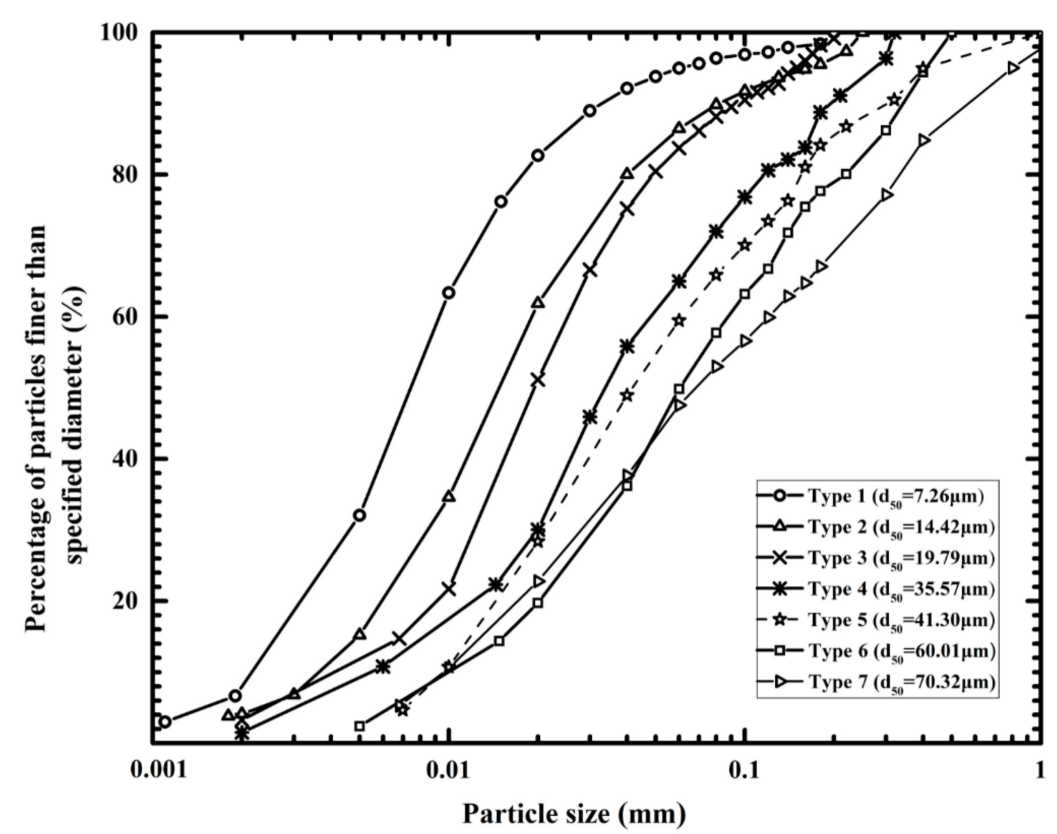

Figure 3. Measured cumulative grain size distribution. The median grain sizes of sediment types 1-7 varied between $7.26 \mu \mathrm{m}$ and $70.32 \mu \mathrm{m}$. 


\subsection{Test Materials}

Seven types of silty sediments were tested in this study. The sediments were dried in an oven at a temperature of $105^{\circ} \mathrm{C}$ for $12 \mathrm{~h}$. The dried sediments were broken up and sieved through a $1.0 \mathrm{~mm}$ mesh to remove impurities such as fibers, small stones, and shellfish. Then, an ultrasonic vibrator was used to break up the floc structure and to disperse the sediment particles in order to minimize the effect of flocculation on grain size analysis [34]. Grain size distribution for the sediment was evaluated using a TZC-4 particle diameter analyzer (Shanghai Tongfang Instrument Company, Shanghai, China), which is an automated sedimentation balance used for determining grain size distribution and median grain size of sediment particles. The measurement range of the analyzer was 1-60 $\mu \mathrm{m}$, and the accuracy of the sedimentation balance was $0.1 \mathrm{mg}$. The measured grain size distributions of these soils are plotted in Figure 3.

Median grain size, specific gravity, uniformity coefficient, and standard deviation of grain size of all seven sediment types are tabulated in Table 1.

Table 1. Physical properties of the tested silty sediments.

\begin{tabular}{cccccccc}
\hline Properties & Type 1 & Type 2 & Type 3 & Type 4 & Type 5 & Type 6 & Type 7 \\
\hline Specific gravity $G_{s}$ & 2.73 & 2.72 & 2.70 & 2.71 & 2.69 & 2.65 & 2.63 \\
Median grain size $d_{50}(\mu \mathrm{m})$ & 7.26 & 14.42 & 19.79 & 35.57 & 41.30 & 60.01 & 70.32 \\
Uniformity coefficient $\sigma_{g}$ & 2.91 & 3.17 & 2.93 & 3.97 & 3.90 & 4.20 & 4.76 \\
Standard deviation of the grain size $(\mu \mathrm{m})$ & 0.9 & 0.7 & 1.2 & 1.9 & 1.6 & 2.1 & 2.6 \\
\hline
\end{tabular}

The uniformity coefficient $\sigma_{\mathrm{g}}$ in Table 1 is defined as [35]:

$$
\sigma_{g}=\frac{1}{2}\left(\frac{d_{84}}{d_{50}}+\frac{d_{50}}{d_{16}}\right)
$$

where $d_{x}$ is the size of grains that are $\mathrm{x} \%$ (by weight) finer than the specified diameter.

\subsection{Test Procedure}

Before each test, the selected sediment was blended with certain predetermined amount of water using a mechanical mixer and remolded to uniform consistency. Void ratio was recorded. The test procedures are outlined as follows:

(1) In order to reduce the sidewall effect, i.e., to prevent seepage water from flowing through the gap between the soil and inner wall, a thin layer of Vaseline was applied uniformly on the wall of the cutting ring.

(2) The test sample (with known void ratio) was placed in the permeameter.

(3) The permeameter was then sealed hermetically and tightly, and the flow inlet, outlet, and piezometer tubes were connected.

(4) The inlet valve was turned on to let water flow into the permeameter at a steady rate. The bubbles inside the permeameter and piezometer tubes were purged carefully, and the temperature and viscosity of the water were recorded.

(5) When the water flow rate was steady, a certain amount of outflow water was collected, and the corresponding time interval was recorded. The water levels of the piezometer tubes were also observed and recorded.

(6) Each test was performed three times to minimize the measurement error.

\section{Results}

Thirty-five sets of experimental results were obtained. Particle diameter $d_{50}$ was in the range of 7.26-70.32 $\mu \mathrm{m}$ (Table 1), and void ratio was in the range of 0.566-3.467 (Table 2). 
Table 2. Void ratio of the 35 test samples.

\begin{tabular}{ccccccc}
\hline Soil Types & \multicolumn{5}{c}{ Void Ratio $\boldsymbol{~}$} \\
\hline Type 1 & 0.723 & 1.123 & 1.544 & 2.610 & 3.144 & 3.467 \\
Type 2 & 0.599 & 1.026 & 1.318 & 1.606 & 2.083 & 2.548 \\
Type 3 & 0.773 & 1.148 & 1.470 & 1.842 & 2.081 & 2.471 \\
Type 4 & 0.566 & 0.946 & 1.363 & 1.581 & 1.953 & $/$ \\
Type 5 & 0.775 & 1.069 & 1.374 & 1.641 & $/$ & $/$ \\
Type 6 & 1.026 & 1.405 & 1.544 & 1.937 & $/$ & $/$ \\
Type 7 & 0.812 & 1.036 & 1.217 & 1.474 & $/$ & $/$ \\
\hline
\end{tabular}

Based on the measured flow rate and hydraulic head gradient across the test sample, hydraulic conductivity $k(\mathrm{~cm} / \mathrm{s})$ was calculated. The variation of hydraulic conductivity with void ratio $e$ was analyzed as described below.

\subsection{Hydraulic Conductivity of Silty Sediments}

Hydraulic conductivity $k(\mathrm{~cm} / \mathrm{s})$ at various void ratio $e$ for all tested sediment types is plotted in Figure 4.

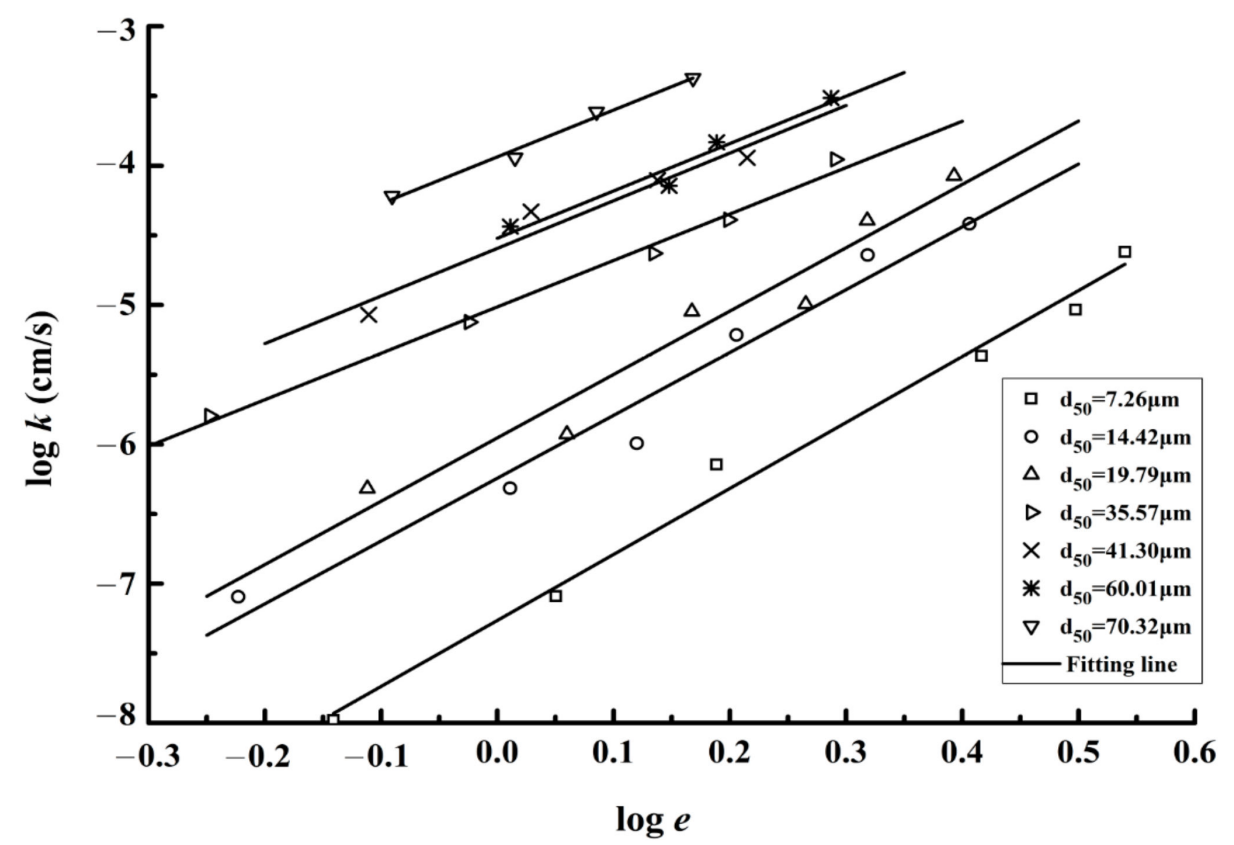

Figure 4. Relationship of hydraulic conductivity $k$ as a function of void ratio $e$. The relationship between $\log k$ and $\log e$ is linear.

It can be seen from Figure 4 that, for a given soil type, hydraulic conductivity $k$ increases with void ratio. There exists an obviously positive linear relationship between $\log k$ and $\log e$, which can be represented by a simple linear function [15] as follow:

$$
\log k=a+b(\log e)
$$

where $a$ and $b$ are the intercept and slope of the fitted straight line. In several empirical models, the parameters $a$ and $b$ are determined as constant, and the logarithmic value of hydraulic conductivity is treated as a simple linear function of the logarithmic value of void ratio [36]. However, the experimental results in Figure 4 show that particle diameter may have certain important effects on hydraulic conductivity in silty sediments, and the parameters $a$ and $b$ of different soil types may be identified and distinguished based on the value of particle diameter $d_{50}$. Figure 5 shows that a linear relationship exists between parameters $a, b$ and particle diameter $d_{50}$. 


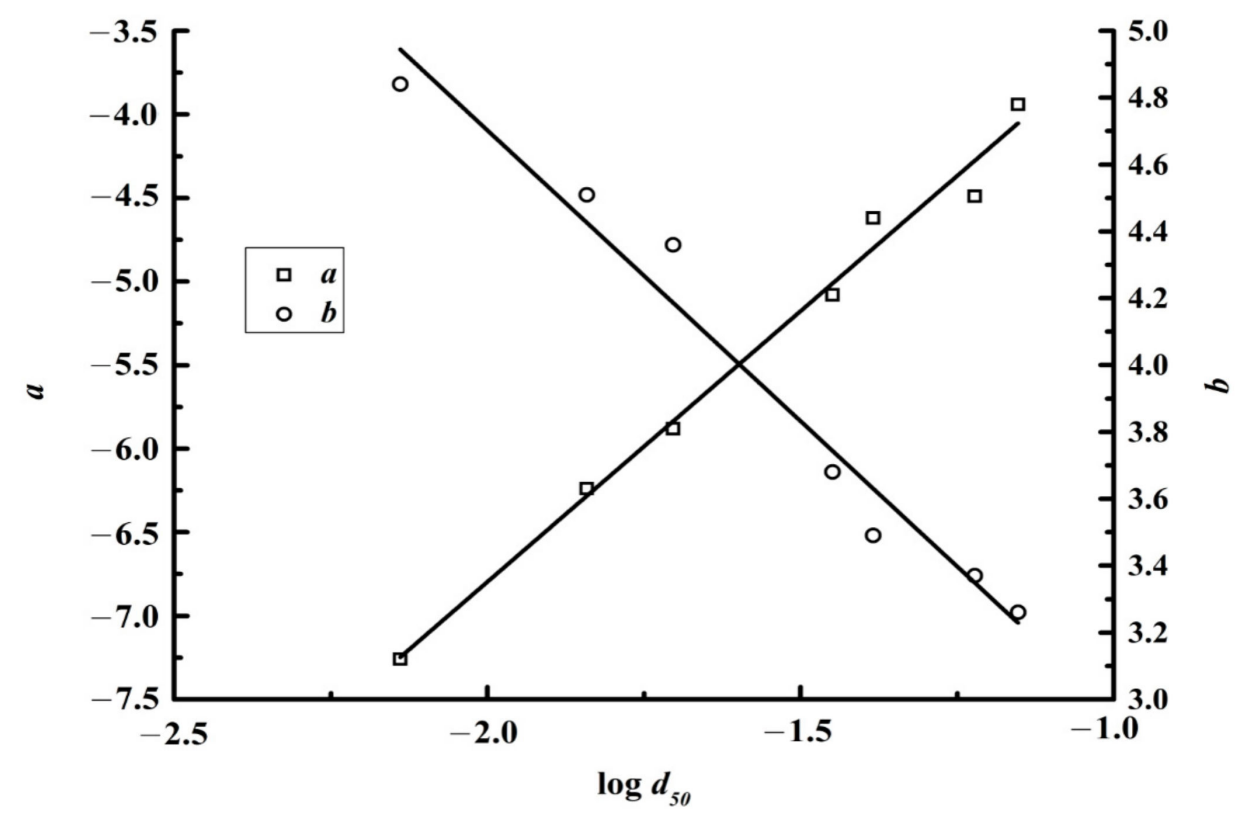

Figure 5. Relationship of parameters $a, b$ and $d_{50}$. Both $a$ and $b$ appear to vary linearly with $d_{50}$.

It is clear then that hydraulic conductivity of silty sediments is dependent on void ratio $e$ and particle diameter $d_{50}$. By performing linear regression analysis, a best fit relationship was obtained to correlate $\log k, \log e$, and $\log d_{50}$, as follow:

$$
\log k=-5.66(\log e)+3.32\left(\log d_{50}\right)-5.38(\log e)\left(\log d_{50}\right)-0.02
$$

and $k(\mathrm{~cm} / \mathrm{s})$ may be expressed in an exponential form as follow:

$$
k=10^{-5.66(\log e)+3.32\left(\log d_{50}\right)-5.38(\log e)\left(\log d_{50}\right)-0.02}
$$

The coefficient of correlation $R^{2}$ and standard deviation are 0.93 and 0.30 , respectively.

Experimental data of Zhang et al. [1] and Chapui and Robert [21] are also used to verify equation (12), and the reported particle diameters $d_{50}$ were in the range of $45-87 \mu \mathrm{m}$ and 3.1-6.17 $\mu \mathrm{m}$, and void ratios were in the range of $0.26-0.41$ and $1-4$, respectively.

In addition, two widely used equations are also included here for comparison. One is the Kozeny-Carman Equation (6), and the other is Equation (7) proposed by Chen et al. [25].

Figure 6 shows the measured and computed hydraulic conductivity using Equations (6), (7) and (12).

Figure 6 indicates that the predicted hydraulic conductivity of silty sediment using Equations (6) and (7) produces a large error. Generally, the computed values using Equations (6) and (7) are much smaller than the measured values except for several data points. Therefore, these two equations may be considered weakly applicable to estimating hydraulic conductivity of a silty sediment. It can be seen that the proposed Equation (12) provides a good estimate of $k$, and almost all the computed $k$ values for these soils fit into the band between the lower bound of one third $(y=x / 3)$ and the upper bound of three $(y=3 x)$ times the value. Therefore, one may conclude that Equation (12) is applicable to estimating hydraulic conductivity $k$ in silty sediments with particle diameter, $d_{50}(3.1 \mu \mathrm{m}<$ $\left.d_{50}<87 \mu \mathrm{m}\right)$ and void ratio, $e(0.26<e<4)$.

\subsection{Seepage Resistance for Seepage Flow in Silty Sediments}

The seepage flow in silty cohesive soils follows the path of a very complex capillary drainage conduit through the pore spaces of the soil matrix. For the simplicity of analysis, one may assume that the sediment particles are spherical and the seepage pathway is a bundle of tortuous capillaries with a uniform circular cross section and diameter. Gener- 
ally, for the steady uniform flow in a uniform pipe, the total water head drop $h_{f}$ can be estimated by:

$$
h_{f}=\lambda \frac{L}{d} \frac{v_{0}^{2}}{2 g}
$$

where $\lambda$ is Darcy-Weisbach friction factor, $L$ is length of flow path, $d$ is diameter of the pipe, $v_{0}$ is flow velocity, and $g$ is the gravitational constant.

The total water head loss $h_{f}$ can be calculated by:

$$
h_{f}=\frac{\Delta p}{\rho g}
$$

where $\Delta p(\mathrm{~Pa})$ is total pressure difference between the inlet and outlet, and $\rho$ is fluid density.

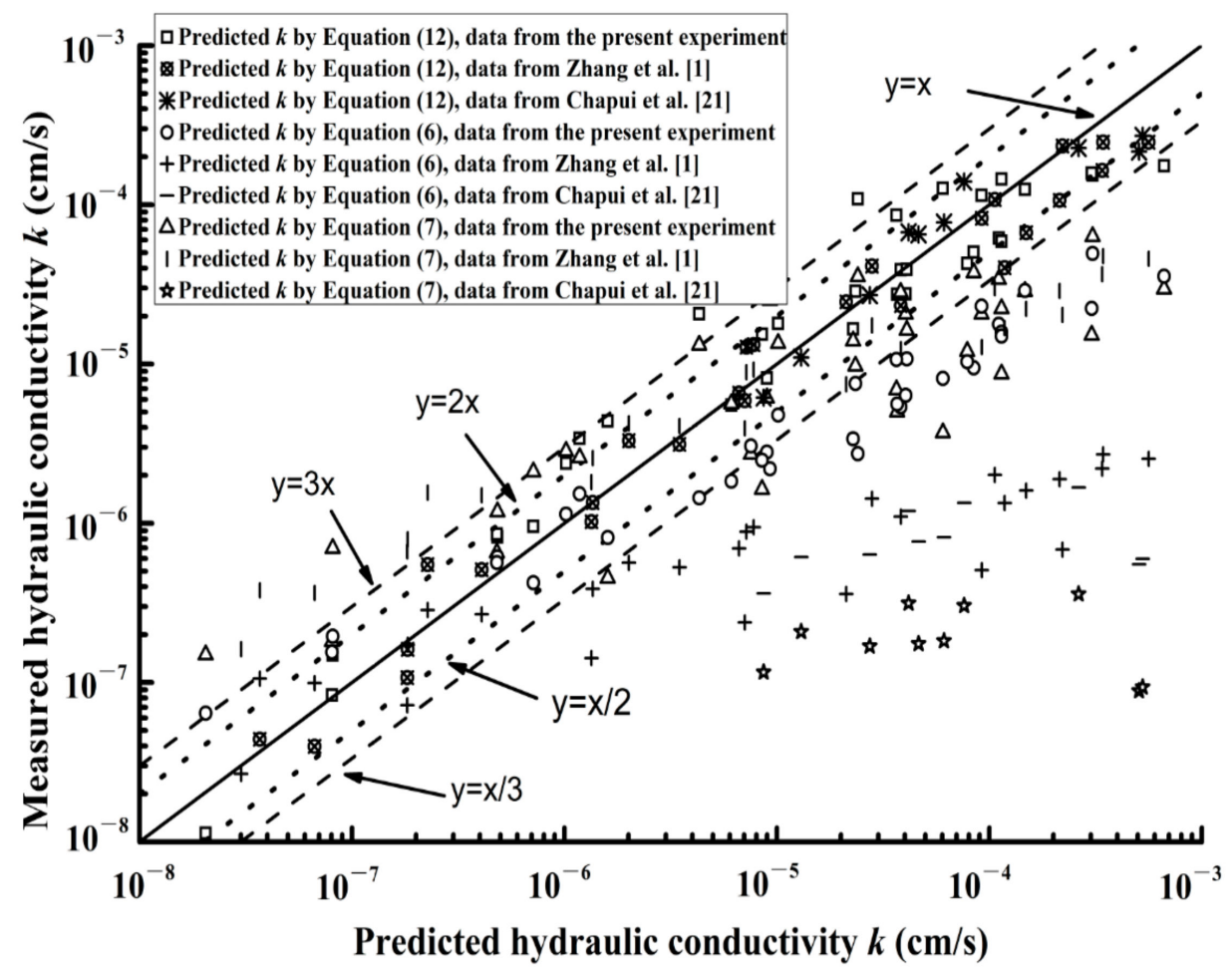

Figure 6. Computed (Equations (6), (7), and (12)) and measured hydraulic conductivity $k$ for the data reported by Zhang et al. [1], Chapui and Robert [21], and the present study. It can be seen that Equation (12) performs better than Equations (6) and (7).

Presumably, for the flow in microscopic drainage conduits, the total pressure drop can be estimated using Equation (13). The microscopic drainage conduits in porous media are analogous to a group of circular capillaries parallel to the direction of flow [37]. These capillaries are tortuous and of complicated shape but may be viewed as tubes with a constant cross-sectional area, on average. The actual length of the flow path is $L=L_{0} \tau$, where $L_{0}$ is straight length or thickness of a test sample in the permeameter, and $\tau$ is tortuosity of the drainage conduits. According to $\mathrm{Yu}$ and $\mathrm{Li}$ [38], $\tau$ is a function of porosity, $\varepsilon$, which can be given by:

$$
\tau=\frac{1}{2}\left(1+\frac{1}{2} \sqrt{1-\varepsilon}+\sqrt{1-\varepsilon} \frac{\sqrt{\left(\frac{1}{\sqrt{1-\varepsilon}}-1\right)^{2}+\frac{1}{4}}}{1-\sqrt{1-\varepsilon}}\right)
$$

$d$ is defined as the equivalent drainage-conduit diameter. For a tube flow, the diameter $d$ and hydraulic radius $R_{h}$ are related as $d=2 r=4 R_{h}$, where $r$ is the radius of the drainage 
conduit. According to Ergun [28], $R_{h}$ is defined by $R_{h}=\varepsilon / \alpha$ with the specific area of solid, $\alpha=6(1-\varepsilon) / d_{s}$, where $d_{s}$ is the particle diameter. Thus, the conduit diameter $d$ can be expressed as:

$$
d=\frac{2 \varepsilon d_{s}}{3(1-\varepsilon)}
$$

The actual velocity of the fluid is given by $v_{0}=v / \varepsilon$, where $v$ is the average velocity. $v$ is expressed as:

$$
v=\frac{q_{t}}{A}=\frac{\Delta m}{\rho A \Delta t}
$$

where $q_{t}$ is the volume of outlet flow per unit time, $A$ is the cross-sectional seepage area, and $\Delta m$ is the mass of the flow within a seepage time interval $\Delta t$.

Finally, the total pressure drop may be rewritten as:

$$
\frac{\Delta p}{\rho g}=h_{f}=\lambda \cdot \frac{3 L_{0} \tau(1-\varepsilon)}{2 \varepsilon d_{s}} \cdot \frac{v^{2}}{2 g}
$$

and the friction factor is given as:

$$
\lambda=\frac{4}{3} \frac{\Delta p}{L_{0} \tau} \frac{d_{s}}{\rho v^{2}} \frac{\varepsilon^{3}}{(1-\varepsilon)}
$$

The particle Reynolds number is introduced to describe the flow regime, and is defined as:

$$
R_{e}=\frac{\rho v_{0} d_{s}}{\mu}
$$

where $\mu$ is the dynamic viscosity of water and $d_{s}$ is replaced by the median size $d_{50}$.

Hence, $\lambda$ and the corresponding $R_{e}$ during the seepage process can be calculated. Based on the experimental data obtained in this study, the variation of seepage friction factor or resistance and particle Reynolds number is listed in Figure 7. Detailed data is shown in Supplementary Materials.

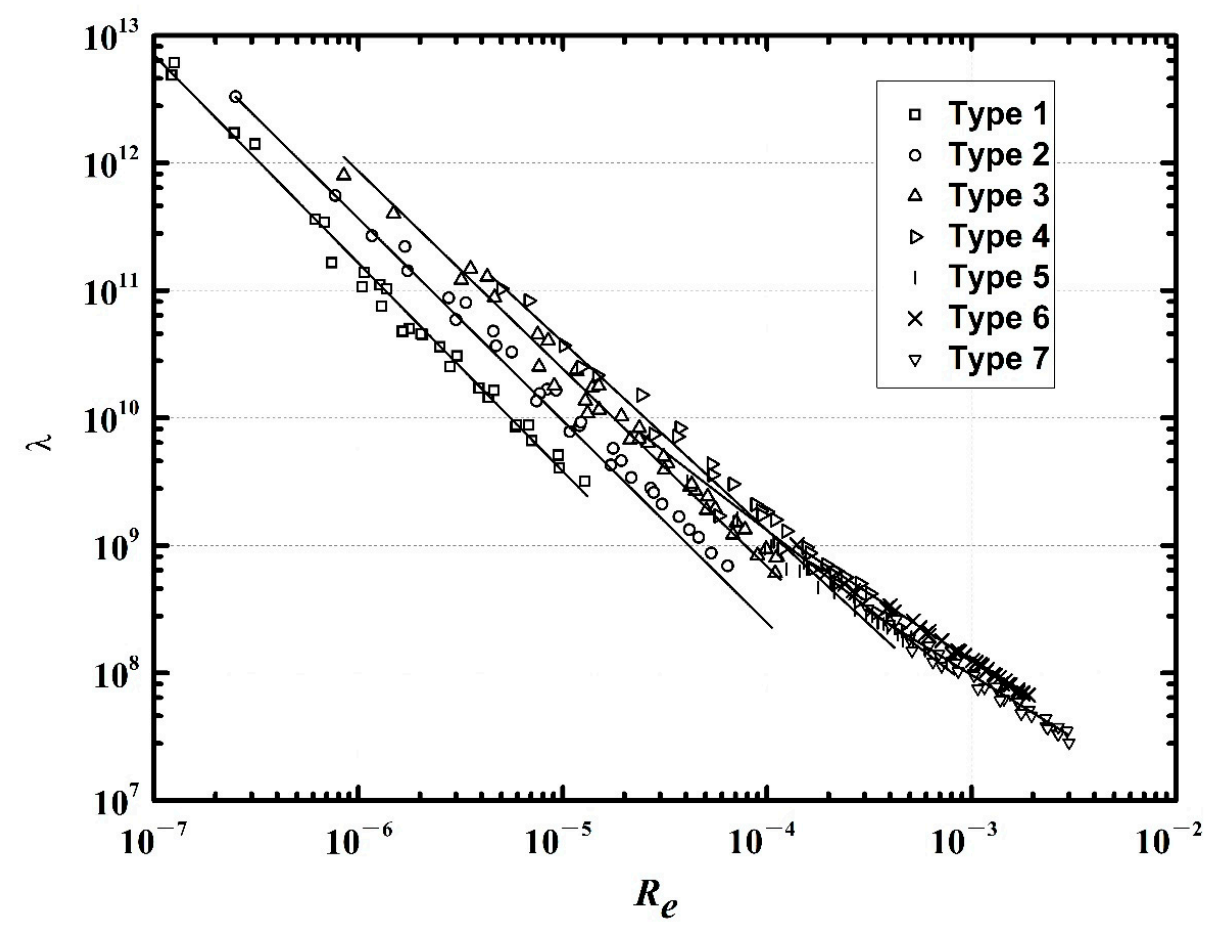

Figure 7. Seepage friction factor, $\lambda$ as a function of particle Reynolds number, $R_{e}$. The $\lambda$ versus $R_{e}$ curve is distinct for a certain sediment type. 
It is clear from Figure 7 that for flow seepage in each type of silty sediment, the seepage resistance or friction factor is linear with Reynolds number. The larger the Reynolds number, the smaller the seepage resistance. In addition, the variation of the resistance against Reynolds number is distinct for a certain sediment type, regardless of its porosity (or water content), and the slopes of the $\lambda$ versus $R_{e}$ curves vary with sediment type. For the type 1 sediment, where $d_{50}$ is the smallest $(7.26 \mu \mathrm{m})$, the $\lambda$ - $R_{e}$ curve is the steepest. However, the slope of the $\lambda$ versus $R_{e}$ curves decreases with the increase of median grain size. When grain size is larger than $60 \mu \mathrm{m}$ (e.g., sediment type 6 and type 7), the logarithmic $\lambda-R_{e}$ line tends to assume a gentle slope of -1 . It may be inferred that when grain size is larger than $60 \mu \mathrm{m}$, the formulae which are used to calculate hydraulic resistance in coarse-grained porous media may be also applicable.

According to Figure 7, one may deduce that the general relationship between $\lambda$ and $R_{e}$ for seepage flow in silty sediments can be expressed in the following form:

$$
\lambda \frac{1-\varepsilon}{\varepsilon}=f R_{e}^{m}, m<-1
$$

where $m$ is the slope of $\lambda$ versus $R_{e}$ curve in the log-log plot. Here, $m$ is related to particle diameter $d_{50}$ and uniformity coefficient $\sigma_{g}$. The coefficient $f$ may not be a constant and depends on $d_{50}$ and $\sigma_{g}$ as well. Introducing the principle of dimensional analysis, the dimensionless particle diameter $d_{*}$ is introduced to replace the median particle diameter, which is commonly defined as [39]:

$$
d_{*}=d_{50}\left[g\left(\rho_{s}-\rho\right) /\left(\rho v^{2}\right)\right]^{\frac{1}{3}}
$$

The values of $m$ and $f$ for the seven types of sediments are listed in Table 3 and Figures 8 and 9 . Only type $1-5$ sediments as the corresponding $m$-values are less than -1 .

Table 3. The values of $m$ and $f$ for types $1-5$ sediments.

\begin{tabular}{cccccc}
\hline Sediment Type & $\boldsymbol{d}_{50}(\boldsymbol{\mu m})$ & $\boldsymbol{d} *$ & $\boldsymbol{d}_{*} / \sigma_{g}$ & $\boldsymbol{m}$ & $f$ \\
\hline Type 1 & 7.26 & 0.187 & 0.064 & -1.607 & 26.75 \\
Type 2 & 14.42 & 0.370 & 0.117 & -1.521 & 123.22 \\
Type 3 & 19.79 & 0.505 & 0.172 & -1.490 & 425.22 \\
Type 4 & 35.57 & 0.910 & 0.230 & -1.363 & 1548.70 \\
Type 5 & 41.30 & 1.053 & 0.270 & -1.096 & 15367 \\
\hline
\end{tabular}

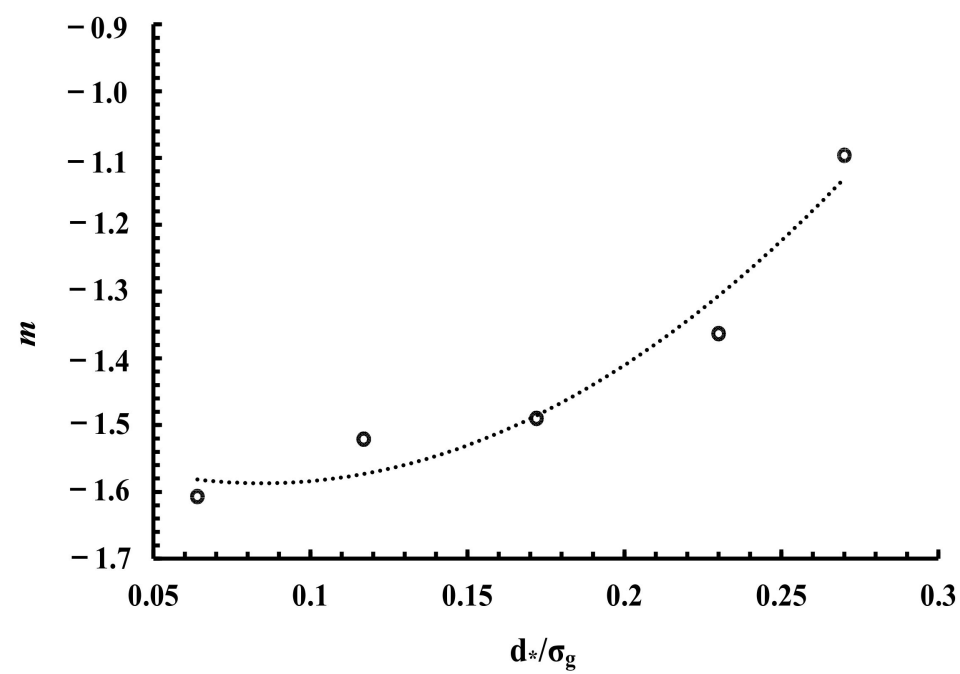

Figure 8. Distribution of $m$ as a function of $d_{*} / \sigma_{g}$. The value of $m$ increases with $d_{*} / \sigma_{g}$. 


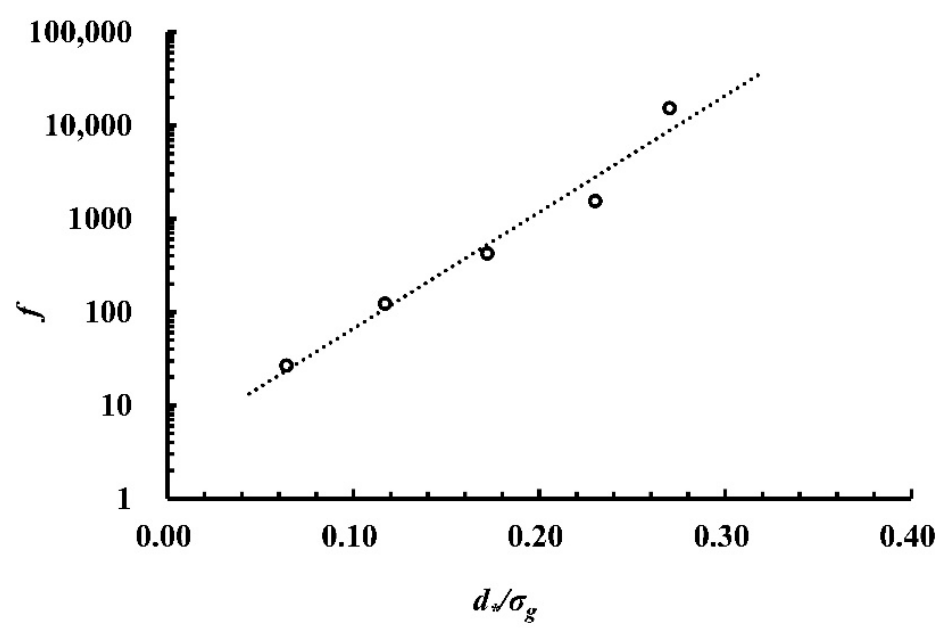

Figure 9. Distribution of $f$ against $d_{*} / \sigma_{g}$. The value of $f$ increases with $d_{*} / \sigma_{g}$.

It can be seen in Figures 8 and 9 that both parameters $m$ and $f$ can be expressed as a function of $d_{*} / \sigma_{g}$, and can be respectively expressed as:

$$
m=16.03\left(\frac{d_{*}}{\sigma_{g}}\right)^{2}-3.22 \frac{d_{*}}{\sigma_{g}}-1.58
$$

And

$$
f=0.32 e^{35.75 \frac{d_{*}}{\sigma_{g}}}
$$

Finally, the relationship of $\lambda$ with $R_{e}$ in fine silty sediments can be rewritten as:

$$
\lambda=0.32\left(\frac{\varepsilon}{1-\varepsilon}\right) e^{35.75 \frac{d_{*}}{\sigma_{g}}} R_{e}^{16.03\left(\frac{d_{*}}{\sigma_{g}}\right)^{2}-3.22 \frac{d_{*}}{\sigma_{g}}-1.58}
$$

\section{Discussions}

Seepage resistance versus Reynolds number obtained in the present study (for silty sediments) and by other researchers [40-48] (for porous media mainly composed of coarse particles) are plotted together in Figure 10.

The results from the present experiments and other studies all show the same trend, i.e., the friction factor increases consistently with a decreasing Reynolds number, and the relationship of flow resistance and Reynolds number is linear in the log-log plot. It is also clear from Figure 10 that for flow through coarse sediment, the slope of $\lambda-R_{e}$ curve on the log-log plot is -1 , so that $\lambda$ as a function of $R_{e}$ is usually expressed as $\lambda=A / R_{e}$. The value of the coefficient $A$ could range from 150 to 200, and is known to be mainly influenced by particle shapes, grain sizes, porosities of the porous medium, and fluid properties [42]. Generally, $A=150$ is accepted for flow which may be described by the power law, and $A=180$ is commonly used in the case of a Newtonian fluid. Seepage flow in coarse sediments is mainly due to free-flowing fluid such that the flow resistance is strongly affected by an individual soil particle, and each type of coarse particle has a different "roughness". In contrast to seepage flow through coarse sediments, seepage flow through silty sediments is affected by the surface roughness of the particles, and the effects of fluid viscosity for flow through very small interconnected pores. In some cases, the effect of viscosity dominates the behavior of the seepage flow. As the grain size is finer, the corresponding specific surface area is larger, and the effects of viscosity much greater. This enhances the ability of sediment particles to "bind" with water, which results in larger flow resistance in silty sediments. As described in Section 3.2, for flow in silty sediments, the slope of $\lambda-R_{e}$ curve is variable, and is dependent on the sediment properties, including grain size and uniformity coefficient. Generally, the slope of the $\lambda-R_{e}$ curve is smaller 
for the case of finer grain size. For the two types of sediments (type 6 and type 7), grain sizes are relatively large (60.01 and $70.32 \mu \mathrm{m}$, respectively), and the slopes of both $\lambda-R_{e}$ curves $(\log -\log )$ are nearly -1 . The relationships between $\lambda$ and $R_{e}$ of these two sediment types agree well with the results obtained by Fancher and Lewis [41], and can be expressed as $\lambda=A / R_{e}$. However, for the other sediments (types 1-5), the values of the slopes of $\lambda-R_{e}$ curves $(\log -\log )$ are less than -1 , and the $\lambda-R_{e}$ curves are steeper than those of the coarse-grain sediments. The sediment with the least grain size $\left(d_{50}=7.26 \mu \mathrm{m}\right)$ had the steepest slope $(-1.63)$.

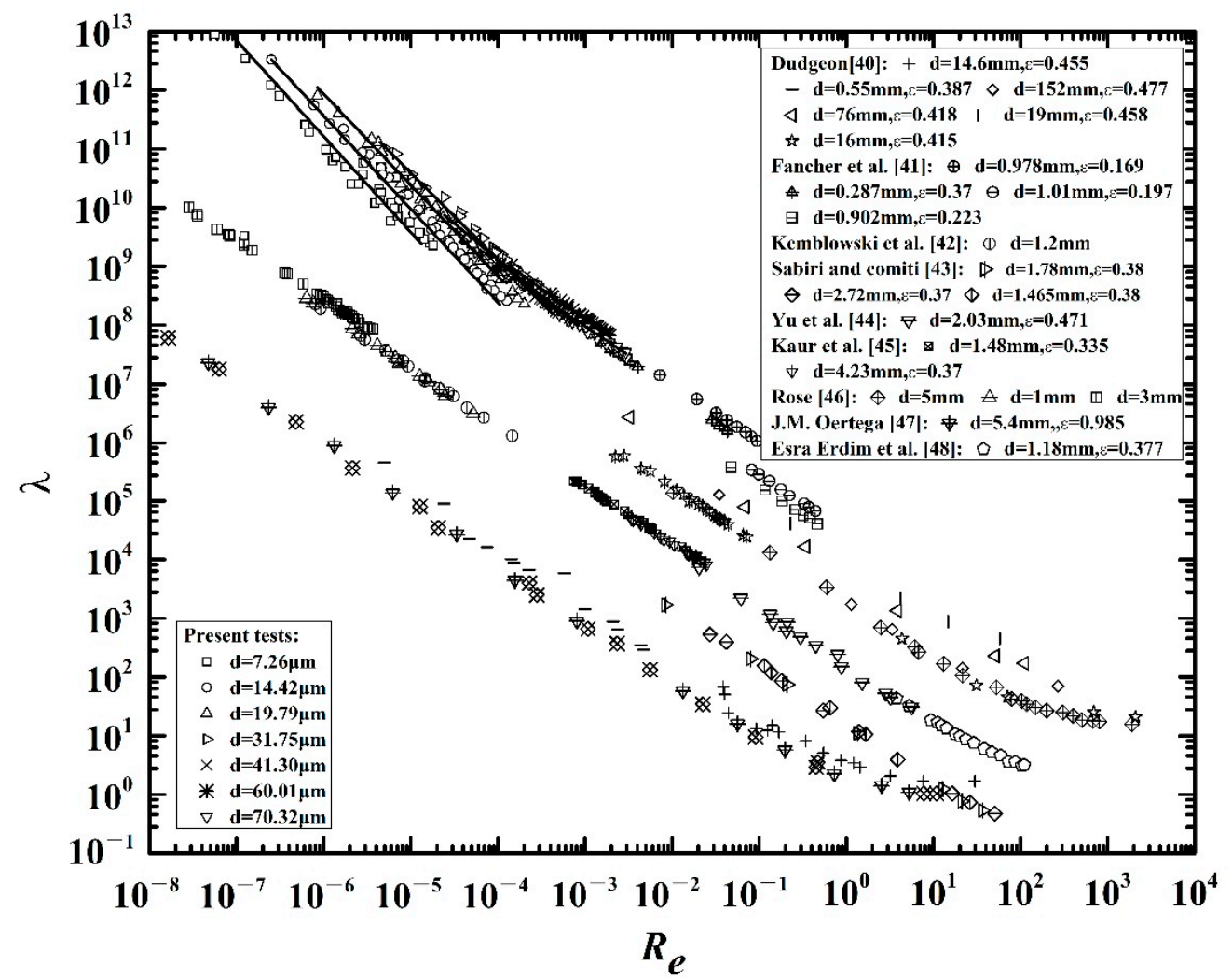

Figure 10. A comparison of resistance factor based on the results obtained in the present study and those reported by other researchers. The values of $\lambda$ in silty sediments are greater than those in coarse porous media at the same Reynolds number. The slope of $\lambda-R_{e}$ curve (log-log) for coarse sediments is -1 , while it is variable for silty sediments.

In addition, the salinity of the dredged silty sediments may also play an important role on hydraulic conductivity and seepage resistance, as salinity may alter the chemical bonds, surface charge characteristics and rheological properties of the sediments. However, the effect of salinity may be complex and is not considered in the present study. Such issue needs further investigation.

\section{Conclusions}

In this study, hydraulic conductivity as well as seepage resistance in silty sediments have been investigated extensively. Thirty-five sets of seepage tests were conducted using seven types of silt sediment samples and at various void ratios. The variation of hydraulic conductivity as a function of void ratio was analyzed. The equation for estimating hydraulic conductivity was proposed and verified with data reported by others. The following conclusions are drawn from the findings of this study:

(1) Hydraulic conductivity $k$ is closely related to void ratio $e$ and particle diameter $d_{50}$ in silty sediments, and it was found that $\log k$ is a linear function of $\log e$. 
(2) An empirical equation for the estimation of hydraulic conductivity was proposed, and was found applicable for particle grain size, $d_{50}\left(3.1 \mu \mathrm{m}<d_{50}<87 \mu \mathrm{m}\right)$ and sediment void ratio $e(0.26<e<4)$.

(3) The friction resistance to seepage flow in silty sediments exhibits distinct characteristics similar to seepage flow in coarse-grained sediments. The slopes of $\lambda$ versus $R_{e}$ curves for seepage in silty sediments are variable and the value of the slope (log-log plot) decreases with increasing grain size, while the slope remains constant $(-1)$ for flow in coarse-grained sediments.

(4) The formulae for calculating the seepage friction factor in coarse-grained sediments are not applicable for silty sediments. A formula for calculating $\lambda$ in silty sediments has been proposed. The value of $\lambda$ in silty sediments is larger than that in coarsegrained sediments for the same Reynolds number $R_{e}$.

Supplementary Materials: The detailed data is available online at https:/ / www.mdpi.com/2073-4 $441 / 13 / 1 / 75 /$ s1.

Author Contributions: Conceptualization, data curation, formal analysis, investigation, validation, writing-Original draft (W.Z.); methodology, software, writing—Review and editing (M.Z.); data curation, resources, software (H.S.); supervision, funding acquisition (G.Y.). All authors have read and agreed to the published version of the manuscript.

Funding: This research was funded by The National Natural Science Foundation of China, grant number 51779137.

Institutional Review Board Statement: Not applicable.

Informed Consent Statement: Not applicable.

Data Availability Statement: Data is contained within the article or Supplementary Material.

Acknowledgments: The authors gratefully acknowledge the financial support provided by the National Natural Science Foundation of China (grant number 51779137). The authors are thankful to the editors and anonymous reviewers for their valuable comments and suggestions to improve the quality of the paper.

Conflicts of Interest: The authors declare no conflicts of interests. The funders had no role in the design of the study; in the collection, analyses, or interpretation of data; in the writing of the manuscript, or in the decision to publish the results.

\section{References}

1. Zhang, M.; Zhu, X.; Yu, G.; Yan, J.; Wang, X.; Chen, M.; Wang, W. Permeability of muddy clay and settlement simulation. Ocean Eng. 2015, 104, 521-529. [CrossRef]

2. Wu, D.Q.; Guo, L. Research progress of recycling Singapore solid wastes for land reclamation. Res. Environ. Sci. 2018, 31, 1174-1181.

3. Vikolainen, V.; Bressers, H.; Lulofs, K. A shift toward building with nature in the dredging and port development industries: Managerial implications for projects in or near natural 2000 areas. Environ. Manag. 2014, 54, 3-13. [CrossRef] [PubMed]

4. Zhu, W.; Yan, J.; Yu, G. Vacuum preloading method for land reclamation using hydraulic filled slurry from the sea: A case study in coastal China. Ocean Eng. 2018, 152, 286-299. [CrossRef]

5. Kaethigesu, T. Validity of Darcy's Law for Low-Gradient Saturated flow through Bentonite and Sand Mixtures. Ph.D. Thesis, University of Manitoba, Winnipeg, MB, Canada, 1994.

6. Sondergaard, M.; Jensen, J.P.; Jeppesen, E. Role of sediment and internal loading of phosphorus in shallow lakes. Hydrobiologia 2003, 506-509, 135-145. [CrossRef]

7. Huang, X.; Liang, P.; Qian, Y. Excess sludge reduction induced by Tubifex tubifex in a recycled sludge reactor. J. Biotechnol. 2007, 127, 443-451. [CrossRef]

8. Wang, L.; Yu, L.; Guo, Z. Seepage induced soil failure and its mitigation during suction caisson installation in silt. J. Offshore Mech. Arct. 2013, 136, 011103. [CrossRef]

9. Steedman, R.S.; Sharp, M.K. Physical modelling analysis of the New Orleans levee breaches. Proc. Inst. Civil Eng. Geotech. Eng. 2011, 164, 353-372. [CrossRef]

10. Olson, K.R.; Morton, L.W. The impacts of 2011 induced levee breaches on agricultural lands of Mississippi river valley. J. Soil Water Conserv. 2012, 67, 5-10. [CrossRef] 
11. Zhu, W.; Zhang, M.; Yu, G.; Petukhov, V.; Mymrin, V.; Gidarakos, E. Flow Resistance in Dredged Soil under a Vacuum Preloading System with Vertical Drainage Boards. J. Coastal Res. 2020, 36, 327-338. [CrossRef]

12. Thiruvengadam, M.; Kumar, G.N.P.; Sivakumar, D.; Mohan, C. Non-dimensional equation of resistance coefficient with Reynolds number of porous media. Indian J. Sci. Technol. 2016, 9, 1-7. [CrossRef]

13. Liu, H.; Li, L.; Birkholzer, J. Unsaturated properties for non-Darcian water flow in clay. J. Hydrol. 2012, 430-431, 173-178. [CrossRef]

14. Chakraborty, D.; Chakraborty, A.; Santra, P.; Tomar, R.K.; Kalra, N. Prediction of hydraulic conductivity of soils from particle-size distribution. Curr. Sci. 2006, 90, 1526-1531.

15. Roque, A.J.; Didier, G. Calculating hydraulic conductivity of fine-grained soils to leachates using linear expressions. Eng. Geol. 2006, 85, 147-157. [CrossRef]

16. Chung, C.K.; Kim, J.H.; Kim, J.; Kim, T. Hydraulic conductivity variation of coarse-fine soil mixture upon mixing ratio. Adv. Civ. Eng. 2018, 2018, 6846584. [CrossRef]

17. Taylor, D.W. Fundamentals of soil mechanics. Soil Sci. 1948, 66, 161. [CrossRef]

18. Mesri, G.; Olson, R.E. Mechanisms controlling the permeability of clays. Clay. Clay Miner. 1971, 19, 151-158. [CrossRef]

19. Samarasinghe, A.M.; Huang, Y.H.; Drnevich, V.P. Permeability and consolidation of normally consolidated soils. J. Geotech. Eng. Division 1982, 108, 835-850. [CrossRef]

20. Ren, X.; Zhao, Y.; Deng, Q.; Li, D.; Wang, D. A relation of hydraulic conductivity-void ratio for soils based on Kozeny-Carman equation. Eng. Geol. 2016, 213, S0013795216302836. [CrossRef]

21. Chapuis, R.P. Predicting the saturated hydraulic conductivity of soils: A review. Bull. Eng. Geol. Environ. 2012, 71, 401-434. [CrossRef]

22. Ishaku, J.M.; Gadzama, E.W.; Kaigama, U. Evaluation of empirical formulae for the determination of hydraulic conductivity based on grain-size analysis. J. Geol. Min. Res. 2011, 3, 105-113.

23. Beyer, W. Hydrogeologische untersuchungen bei der ablagerung von wasserschadstoffen. Z. Fuer Angew. Geol. 1966, 12, 599-606. (In German)

24. Odong, J. Evaluation of empirical formula for determination of hydraulic conductivity based on grain size analysis. J. Am. Sci. 2007, 3, 54-60.

25. Chen, C.Y.; Bullen, A.G.R.; Elnaggar, H.A. Permeability and Related Principles of Coal Refuse. Transp. Res. Rec. 1977, 640, 49-52.

26. David, W.; Lii, C.; Asce, F. Goodbye, Hazen; Hello, KozenyCarman. J. Geotech. Geoenviron. Eng. 1962, 40, $260-261$.

27. Sanzeni, A.; Colleselli, F.; Grazioli, D. Specific surface and hydraulic conductivity of fine-grained soils. J. Geotech. Geoenviron. 2013, 139, 1828-1832. [CrossRef]

28. Ergun, S. Fluid flow through packed columns. Chem. Eng. Prog. 1952, 48, 89-94.

29. Liakopoulos, A.; Sofos, F.; Karakasidis, T.E. Friction factor in nanochannel flows. Microfluid. Nanofluid. 2016, 20, 20-24. [CrossRef]

30. Macdonald, I.F.; El-Sayed, M.S.; Mow, K.; Dullien, F.A.L. Flow through Porous Media—the Ergun Equation Revisited. Ind. Eng. Chem. Fundam. 1979, 18, 199-208. [CrossRef]

31. Moutsopoulos, K.N.; Papaspyros, I.N.E.; Tsihrintzis, V.A. Experimental investigation of inertial flow processes in porous media. J. Hydrol. 2009, 374, 242-254. [CrossRef]

32. Yang, W.; Yu, G.; Tan, S.K.; Wang, H. Rheological properties of dense natural cohesive sediments subject to shear loadings. Int. J. Sediment Res. 2014, 29, 454-470. [CrossRef]

33. Zhang, M.; Yu, G.; Rovere, A.L.; Ranzi, R. Erodibility of fluidized cohesive sediments in unidirectional open flows. Ocean Eng. 2017, 130, 523-530. [CrossRef]

34. Zhang, M.; Yan, J.; Wang, X.; Chen, M.; Zhao, D.; Yu, G. Application of ultrasonic vibrator to sedimentation analysis m23sive sediment grain size. Water Resour. Hydropower Eng. 2014, 45, 100-103. (In Chinese)

35. Yu, G.L.; Lim, S.Y. Modified manning formula for flow in alluvial channels with sand-beds. J. Hydraul. Res. 2003, 41, 597-608. [CrossRef]

36. Dolinar, B. Predicting the hydraulic conductivity of saturated clays using plasticity-value correlations. Appl. Clay Sci. 2009, 45, 90-94. [CrossRef]

37. Carman, P.C. Fluid flow through granular beds. Transp. Inst. Chem. Eng. 1997, 15, 32-48. [CrossRef]

38. Yu, B.; Li, J. A geometry model for tortuosity of flow path in porous media. Chin. Phys. Lett. 2004, 21, $1569-1571$.

39. Zhang, M.; Yu, G. Critical conditions of incipient motion of cohesive sediments. Water Res. Res. 2017, 53, 7798-7815. [CrossRef]

40. Dudgeon, C.R. An experimental study of the flow of water through coarse granular media. Houille Blanche 1966, 7, 785-801. [CrossRef]

41. Fancher, G.H.; Lewis, J.A. Flow of simple fluids through porous materials. Ind. Eng. Chem. 1933, 25, 1139-1147. [CrossRef]

42. Kemblowski, Z.; Michniewicz, M. A new look at the laminar flow of power law fluid through granular beds. Rheol. Acta 1979, 18, 730-739. [CrossRef]

43. Sabiri, N.E.; Comiti, J. Experimental validation of a model allowing pressure gradient determination for non-Newtonian purely viscous fluid-flow through packed beds. Chem. Eng. Sci. 1997, 52, 3589-3592. [CrossRef]

44. Yu, Y.H.; Wen, C.Y.; Bailie, R.C. Power-law fluids flow through multiparticle system. Can. J. Chem. Eng. 2010, 46, 149-154. [CrossRef] 
45. Kaur, N.; Singh, R.; Wanchoo, R.K. Flow of Newtonian and Non-Newtonian fluids through packed beds: An experimental study. Transp. Porous Med. 2011, 90, 655-671. [CrossRef]

46. Rose, H.E. On the resistance coefficient-Reynolds number relationship for fluid flow through a bed of granular material. Proc. Inst. Mech. Eng. 1945, 153, 154-168. [CrossRef]

47. Ortega, J.M. A porous media model for blood flow within reticulated foam. Chem. Eng. Sci. 2013, 99, 59-66. [CrossRef]

48. Erdim, E.; Akgiray, O.; Demir, I. A revisit of pressure drop-flow rate correlations for packed beds of spheres. Powder Technol. 2015, 283, 488-504. [CrossRef] 